\title{
Oxidation Behavior of Mo-Si-B Alloys in Wet Air
}

\author{
Matthew J. Kramer \\ Ames Laboratory, 37 Wilhelm Hall, Iowa State University, Ames, IA 50011 \\ E-mail: mjkramer@ameslab.gov; Telephone: (515) 294-0276; Fax: (515) 294-4291
}

Andrew J. Thom

Ames Laboratory, 142 Spedding Hall, Iowa State University, Ames, IA 50011

E-mail: ajthom@ameslab.gov; Telephone: (515) 294-4064; Fax: (515) 294-4709

Vikas Behrani

Ames Laboratory, 330 Spedding Hall, Iowa State University, Ames, IA 50011

E-mail: behraniv@iastate.edu; Telephone: (515) 294-0709; Fax: (515) 294-4709

Mufit Akinc

Ames Laboratory, 333 Spedding Hall, Iowa State University, Ames, IA 50011

E-mail: makinc@ameslab.gov; Telephone: (515) 294-0744; Fax: (515) 294-4709

\section{Manuscript}

\begin{abstract}
Multiphase composite alloys based on the Mo-Si-B system are candidate materials for ultra-high temperature applications. In non load-bearing uses such as thermal barrier coatings or heat exchangers in fossil fuel burners, these materials may be ideally suited. The present work investigated the effect of water vapor on the oxidation behavior of Mo-Si-B phase assemblages. Three alloys were studied: Alloy $1=\mathrm{Mo}_{5} \mathrm{Si}_{3} \mathrm{~B}_{\mathrm{x}}(\mathrm{T} 1)-\mathrm{MoSi}_{2}-$ $\mathrm{MoB}$, Alloy $2=\mathrm{T} 1-\mathrm{Mo}_{5} \mathrm{SiB}_{2}$ (T2)- $\mathrm{Mo}_{3} \mathrm{Si}$, and Alloy $3=\mathrm{Mo}-\mathrm{T} 2-\mathrm{Mo}_{3} \mathrm{Si}$. Tests were conducted at $1000^{\circ}$ and $1100^{\circ} \mathrm{C}$ in controlled atmospheres of dry air and wet air nominally containing 18,55 , and 150 Torr $\mathrm{H}_{2} \mathrm{O}$. The initial mass loss of each alloy was approximately independent of the test temperature and moisture content of the atmosphere. The magnitude of these initial losses varied according to the Mo content of the alloys. All alloys formed a continuous, external silica scale that protected against further mass change after volatilization of the initially formed $\mathrm{MoO}_{3}$. All alloys experienced a small steady state mass change, but the calculated rates cannot be quantitatively compared due to statistical uncertainty in the individual mass measurements. Of particular interest is that Alloy 3, which contains a significant volume fraction of Mo metal, formed a protective scale. All alloys formed varying amounts of subscale $\mathrm{Mo}$ and $\mathrm{MoO}_{2}$. This implies that oxygen transport through the external silica scale has been significantly reduced. For all alloys, water vapor accelerated the growth of a multiphase interlayer at the silica scale/unoxidized alloy interface. This interlayer is likely composed of fine $\mathrm{Mo}$ and $\mathrm{MoO}_{2}$ that is dispersed within a thin silica matrix. Alloy 3 was particularly sensitive to water accelerated growth of this interlayer. At $1100^{\circ} \mathrm{C}$, the scale thickness after 300 hours increased from about 20 $\mu \mathrm{m}$ in dry air to nearly $100 \mu \mathrm{m}$ in wet air.
\end{abstract}




\section{PURPOSE OF THIS PROJECT}

The Mo-Si-B system offers a variety of in-situ composite microstructures that possess excellent oxidation resistance, superior creep resistance, and semi-metallic electrical conductivity. Work at Ames has shown that components based on the Mo-Si-B system offer the potential for operating temperatures to at least $1600^{\circ} \mathrm{C}$ in air. The proposed work concentrates on novel processing and characterization methods to develop alloys for components in heat exchangers and non-load bearing components in gas turbines that can withstand operating temperatures in excess of $1600^{\circ} \mathrm{C}$ under normal operating conditions for 1000 hours or more.

\section{DISCUSSION OF CURRENT ACTIVITIES}

\section{PREPARATION OF ALLOYS}

Based upon previous work, two oxidatively stable alloys around the $\mathrm{T} 1$ compound were selected for further study [1]. This included Alloy 1 (T1, MoSi, $\mathrm{MoB})$ and Alloy 2 (T1, $\left.\mathrm{Mo}_{5} \mathrm{~B}_{2} \mathrm{Si}_{1} \mathrm{Mo}_{3} \mathrm{Si}\right)$. Alloy $3\left(\mathrm{Mo}, \mathrm{Mo}_{3} \mathrm{Si}\right.$, T2) was also selected because it contains a tough metal phase and thus has promising mechanical properties [2]. Table I gives the nominal elemental composition of these three alloys and their nominal phase proportions.

Table I: Nominal composition and phase proportions of tested alloys

\begin{tabular}{|c||c|c|c||c|c|c|c|c|c||}
\hline \multicolumn{1}{|c||}{} & \multicolumn{3}{c||}{ Wt \% } & \multicolumn{6}{c||}{ Vol \% } \\
\hline Alloy & Mo & Si & B & T1 & MoB & MoSi $_{2}$ & T2 & $\mathbf{M o}_{3}$ Si & Mo \\
\hline 1 & 84.0 & 13.4 & 2.6 & 66 & 22 & 12 & & & \\
\hline 2 & 88.6 & 9.9 & 1.5 & 45 & & & 31 & 24 & \\
\hline 3 & 94.6 & 4.3 & 1.1 & & & & 30 & 27 & 43 \\
\hline
\end{tabular}

Table II: Test matrix for oxidation studies

\begin{tabular}{|c|c|}
\hline Furnace Temp $\left({ }^{\circ} \mathbf{C}\right)$ & $\begin{array}{c}\text { Water Content (Torr } \\
\left.\mathbf{H}_{\mathbf{2}} \mathbf{O}\right)\end{array}$ \\
\hline 1000 & Dry Air \\
\hline 1000 & 55 \\
\hline 1100 & Dry Air \\
\hline 1100 & 18 \\
\hline 1100 & 55 \\
\hline 1100 & 150 \\
\hline
\end{tabular}


Pellets of Alloys 1, 2, and 3 were prepared from the $<15$ $\mu \mathrm{m}$ size fraction of the commercially procured powders. The powder was milled in a WC impact mill, sieved to - 635 mesh $(<20 \mu \mathrm{m})$, uniaxially pressed into pellets, and sintered at $1800^{\circ}-1900^{\circ} \mathrm{C}$ for 2 hours in argon. The Archimedes density of the sintered material for all alloys was greater than 95\% of theoretical density. Figure 1 shows a representative cross-sectional view of sintered material for each of the three alloys.

\section{ALLOY COUPON OXIDATION TESTING}

Sintered pellets of Alloys 1, 2, and 3 were cut into oxidation test coupons. The nominal coupon size was $9 \mathrm{~mm}$ diameter and $1 \mathrm{~mm}$ thick for a nominal surface area of $1 \mathrm{~cm}^{2}$. The rough cut faces of the coupons were polished to a $1 \mu \mathrm{m}$ alumina abrasive finish.

A horizontal tube furnace was configured for conducting oxidation testing to $1100^{\circ} \mathrm{C}$ to determine the effect of $\mathrm{H}_{2} \mathrm{O}$ on the oxidative behavior of the alloys. Flowing compressed air was used as the carrier gas, and the $\mathrm{H}_{2} \mathrm{O}$ content was controlled by bubbling the carrier gas through a temperaturecontrolled water bath. The experiment was conducted in a sealed quartz tube with sample coupons placed in alumina combustion boats. A mass flow controller was used to precisely control the delivery rate of the carrier gas at 75 $\mathrm{ml} /$ minute with the gas stream vented through an oil bubbler. The samples were cooled to room temperature for interrupted mass measurements after 20, 40, 60, 80, 148, 192 , and 304 hours of cumulative exposure at the desired test temperature. Table II gives the experimental test matrix.

The water content of the flowing air was estimated as the equilibrium vapor pressure of water when heated to $20^{\circ} \mathrm{C}$ (18 Torr), $40^{\circ} \mathrm{C}$ (55 Torr), and $60^{\circ} \mathrm{C}$ (150 Torr). This is the maximum possible water content of the air, but the actual water content in the oxidation studies is likely smaller. The actual water content will be later measured using a quadrupole residual gas analyzer.
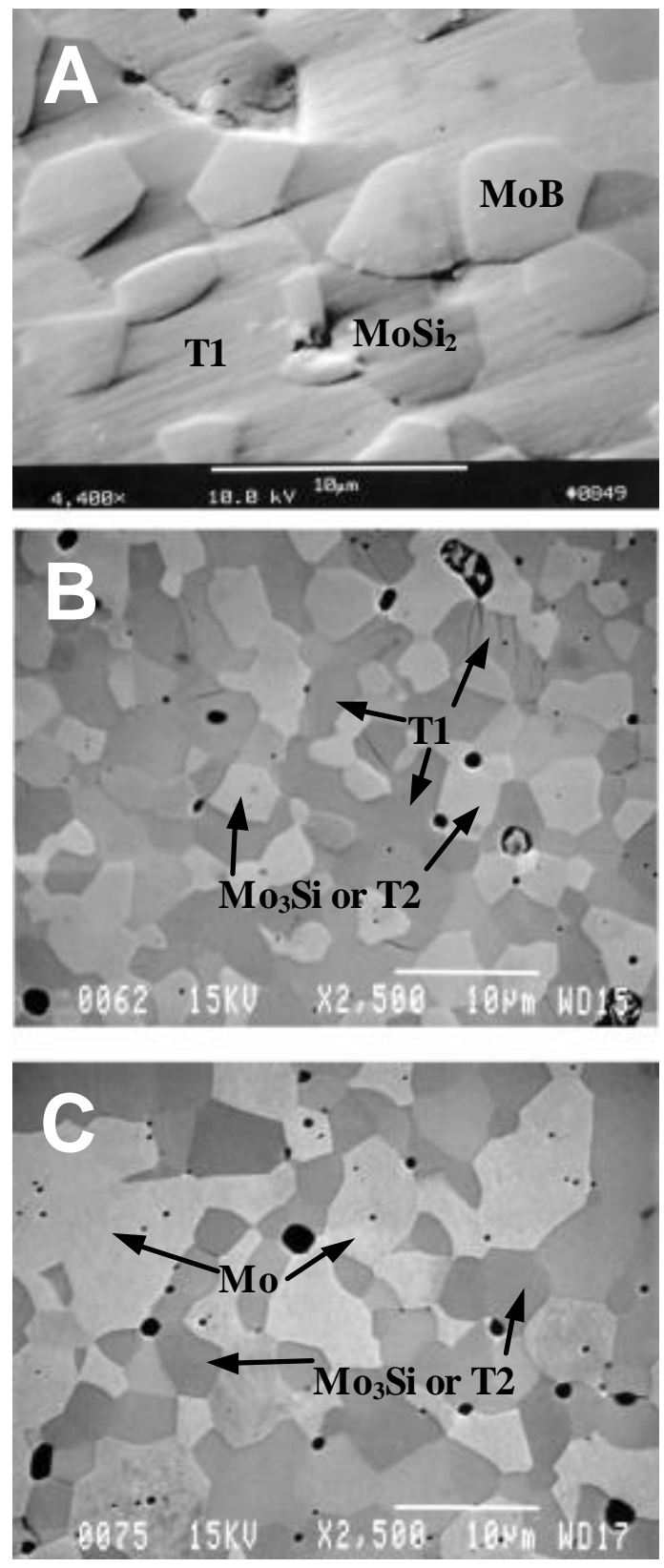

Figure 1: Secondary electron or backscattered electron image of sintered samples of (A) Alloy 1 with T1 matrix, (B) Alloy 2 with microcracked T1 grains, and (C) Alloy 3 with Mo grains containing intragranular porosity. Contrast of $\mathrm{T} 2$ and $\mathrm{Mo}_{3} \mathrm{Si}$ are nearly identical. Small pores and/or pockets of silica are visible as small dark circles. 
The mass change of Alloys 1, 2, and 3 are shown in Figure 2. The initial mass loss of each alloy was approximately independent of the test temperature and moisture content of the atmosphere. The average initial mass losses for Alloys 1, 2, and 3 were 1.6, 7.6, and $51 \mathrm{mg} / \mathrm{cm}^{2}$, respectively.

Measurements were average values based on four samples each of Alloys 1 and 2, and upon three samples each of Alloy 3. The magnitude of these initial losses varied according to the Mo content of the alloys. Alloys 1 and 2, which both contain the oxidation resistant $\mathrm{T} 1$ phase, are similar. The higher overall Mo content of Alloy 2 (88.6 wt\%) compared to Alloy 1 (84.0 $\mathrm{wt} \%$ ) contributed to a five-fold increase in initial mass loss. Alloy 3 contains $94.6 \mathrm{wt} \%$ Mo, and this contributed to a thirty-fold increase in initial mass loss compared to Alloy 1.

The estimated rate constants indicated the tendency for all alloys to undergo either a small steady state mass gain or mass loss. The small steady state changes observed, typically less than $5 \times 10^{-3} \mathrm{mg} / \mathrm{cm}^{2} / \mathrm{hr}$, were not statistically significant based on the uncertainty in the individual mass measurements. However, these data indicated that after the initial mass loss due to the volatilization of $\mathrm{MoO}_{3}$, all three alloys formed stable oxide layers that protected each alloy from rapid mass gain or loss. Of particular interest is the formation of a protective scale on Alloy 3, which contains a significant volume fraction of Mo metal.

The oxidized samples were carefully analyzed by x-ray diffraction (XRD) to identify scale phases. These results are shown in Figure 3. For clarity of the
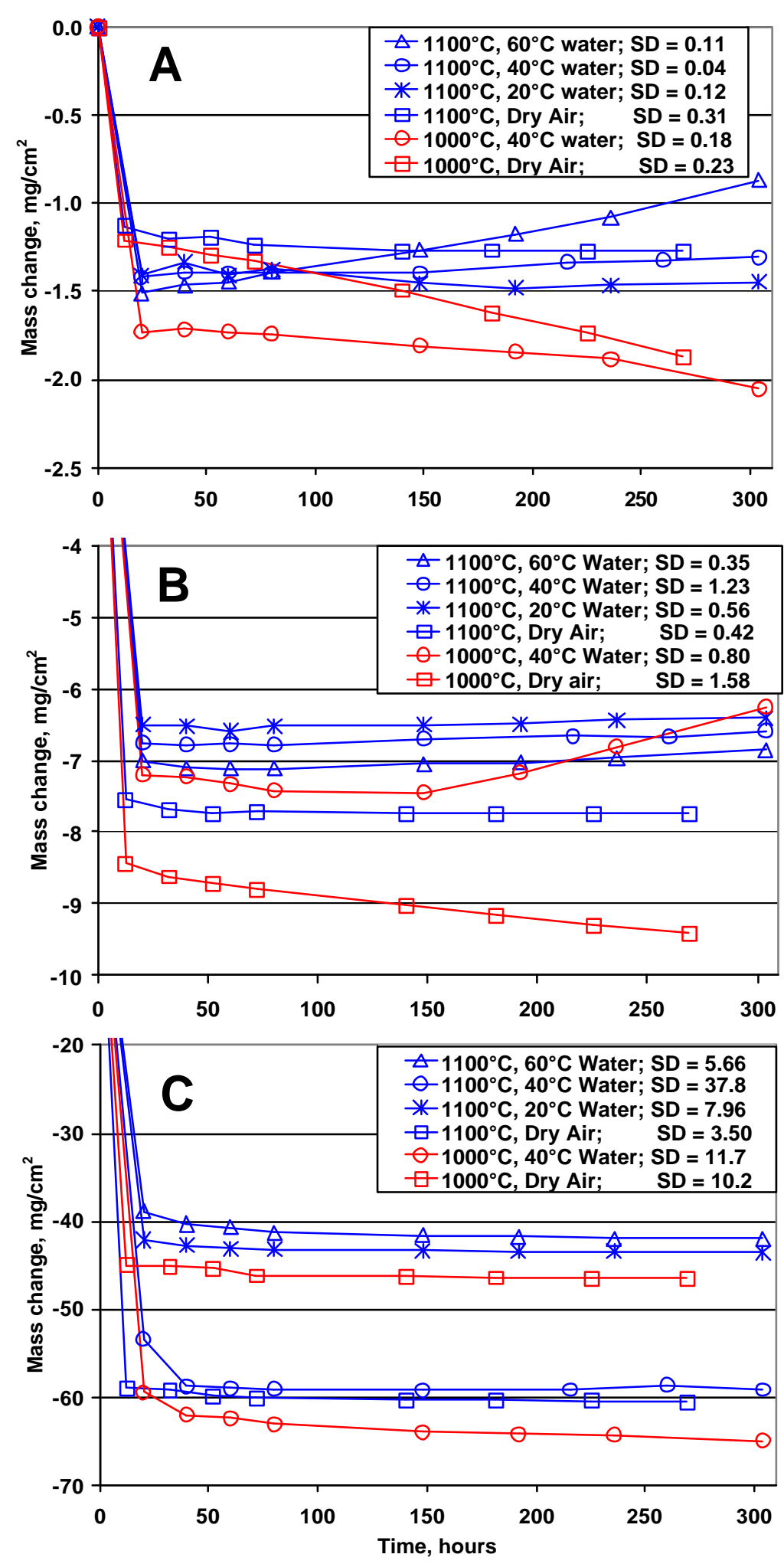

Figure 2: Mass change at $1000^{\circ}$ and $1100^{\circ} \mathrm{C}$ in dry and wet air for (A) Alloy 1, (B) Alloy 2, and (C) Alloy 3. The pooled standard deviation for each run condition is indicated in the graph legend as $\mathrm{SD}$, and this gives an indication of the uncertainty in the measurements. 
graphs, $\mathrm{XRD}$ scans for $1100^{\circ} \mathrm{C}\left(20^{\circ} \mathrm{C}\right.$ water $)$ and $1100^{\circ} \mathrm{C}\left(40^{\circ} \mathrm{C}\right.$ water $)$ were omitted. For Alloy 1 , a thin scale at all conditions is evidenced by visible silicide peaks. Moisture promoted the formation of a thicker scale, as the intensity of the underlying silicide peaks in the corresponding wet pattern diminished.

Elemental Mo was present at all conditions, except for a reduced presence at $1100^{\circ} \mathrm{C}$ in dry air. $\mathrm{MoO}_{2}$ was also observed at all conditions, and the scale at $1000^{\circ} \mathrm{C}$ appeared slightly thicker than at $1100^{\circ} \mathrm{C}$. For Alloy 2, a thin scale in dry air is evidenced by visible silicide peaks from the underlying alloy. However, the extent of silicide peaks was much less than in Alloy 1, and so an overall thicker scale is expected on Alloy 2. Elemental Mo is again present at all conditions and dominates the pattern for $1100^{\circ} \mathrm{C}\left(60^{\circ} \mathrm{C}\right.$ water $) . \mathrm{MoO}_{2}$ is present but in a reduced extent compared to Alloy 1, but $\mathrm{MoO}_{2}$ presence was more strongly indicated at $1000^{\circ} \mathrm{C}\left(40^{\circ} \mathrm{C}\right.$ water $)$. As for Alloy 1, moisture promoted the formation of a thicker scale. For Alloy 3, underlying silicide peaks are only slightly visible at $1100^{\circ} \mathrm{C}$ in dry air, and so thicker scales are generally expected on Alloy 3. In contrast to Alloys 1 and 2, in which elemental Mo is present at all conditions, the scales on Alloy 3 at $1000^{\circ} \mathrm{C}$ do not appear to contain Mo. This may also be a consequence of a thicker scale. Given the generally thinner scale at $1100^{\circ} \mathrm{C}$ in dry air, the detected Mo can't be distinguished as being present in the scale or in the underlying alloy. At $1100^{\circ} \mathrm{C}$ $\left(60^{\circ} \mathrm{C}\right.$ water), the intensity of Mo diminishes at the same time the underlying silicide peaks have disappeared, and so elemental Mo may be present within the scale. $\mathrm{MoO}_{2}$ is present at all conditions, except for a diminished presence at $1100^{\circ} \mathrm{C}$ in dry air.
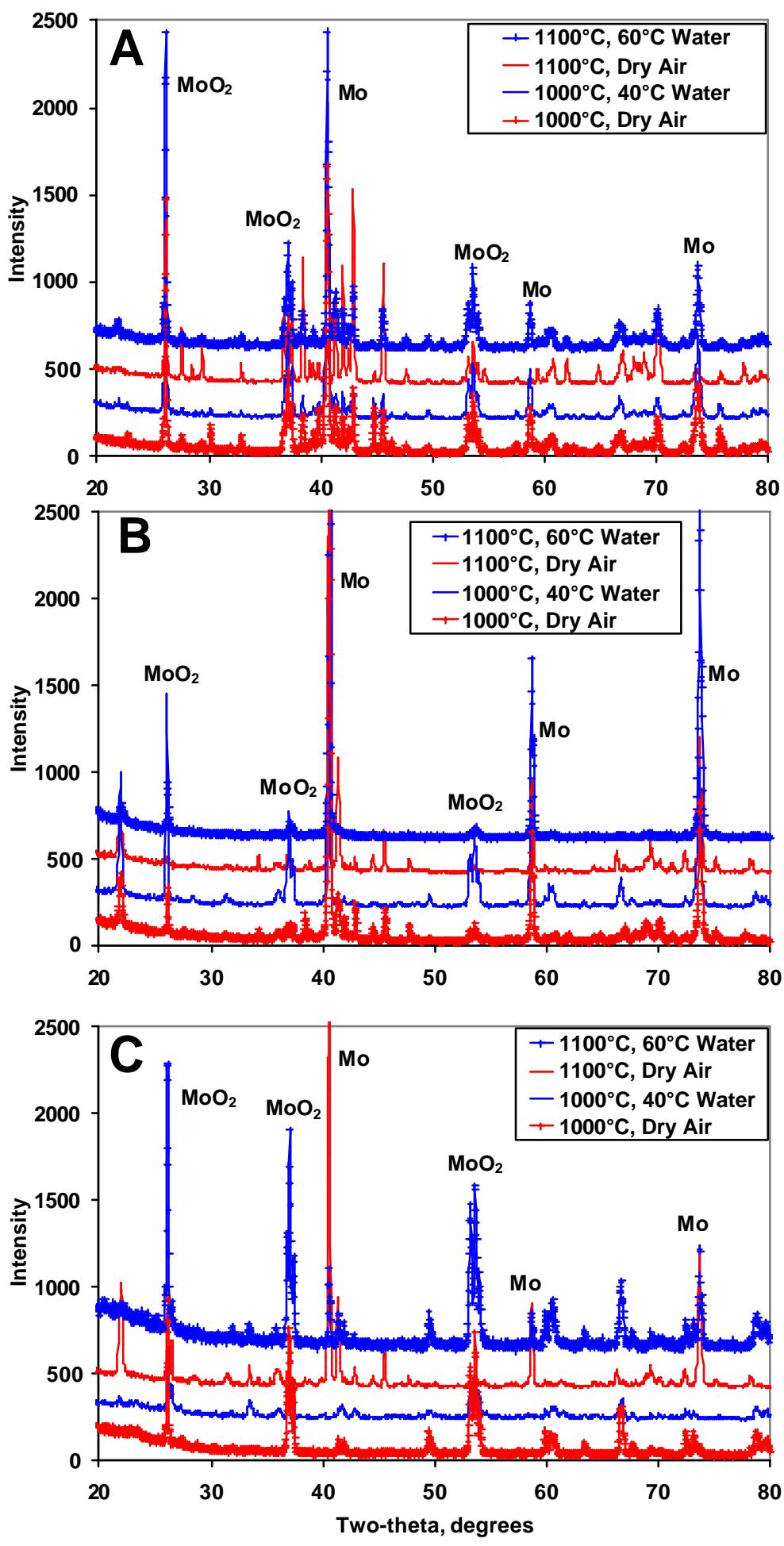

Figure 3: XRD of surface scales formed after oxidation for about 300 hours at $1000^{\circ}$ and $1100^{\circ} \mathrm{C}$ in dry and wet air for (A) Alloy 1, (B) Alloy 2, and (C) Alloy 3. 
Scanning electron microscopy with energy dispersive spectroscopy (SEM/EDS) analysis of the surface of the scales revealed that all samples oxidized at $1100^{\circ} \mathrm{C}$ were covered with a continuous layer of silica. Figure 4B shows the surface of the scale that formed on Alloy 2 oxidized at $1100^{\circ} \mathrm{C}\left(60^{\circ} \mathrm{C}\right.$ water). The scale has a very low density of small, micron sized pores, but is otherwise covered with a continuous silica layer. The scale also showed evidence of crystallization, perhaps as spherulitic cristobalite. For both Alloys 1 and 2, water vapor increases the extent of apparent crystallization. Rigorous analysis of the XRD patterns is needed to better assess the extent of amorphous and crystalline silica in the scale. Alloy 3, seen in Figure 4A, also showed evidence of scale crystallization and long, lathe-like needles composed of silica, perhaps as remnants of $\mathrm{MoO}_{3}$ which evaporated and left an empty shell of silica glass.

Boron evaporation is known to occur during extended exposures at $1150^{\circ} \mathrm{C}$ [3], and boron was not detected by EDS in the surface scales of samples oxidized at $1100^{\circ} \mathrm{C}$ in the present study. However, EDS is relatively insensitive to boron and does not easily yield quantitative measurement of boron. Future ESCA measurements are planned to quantify the boron content of the near surface of the scale. Auger line scan profiles will also be conducted across the scale cross-sections to determine the boron concentration profile through the scale.
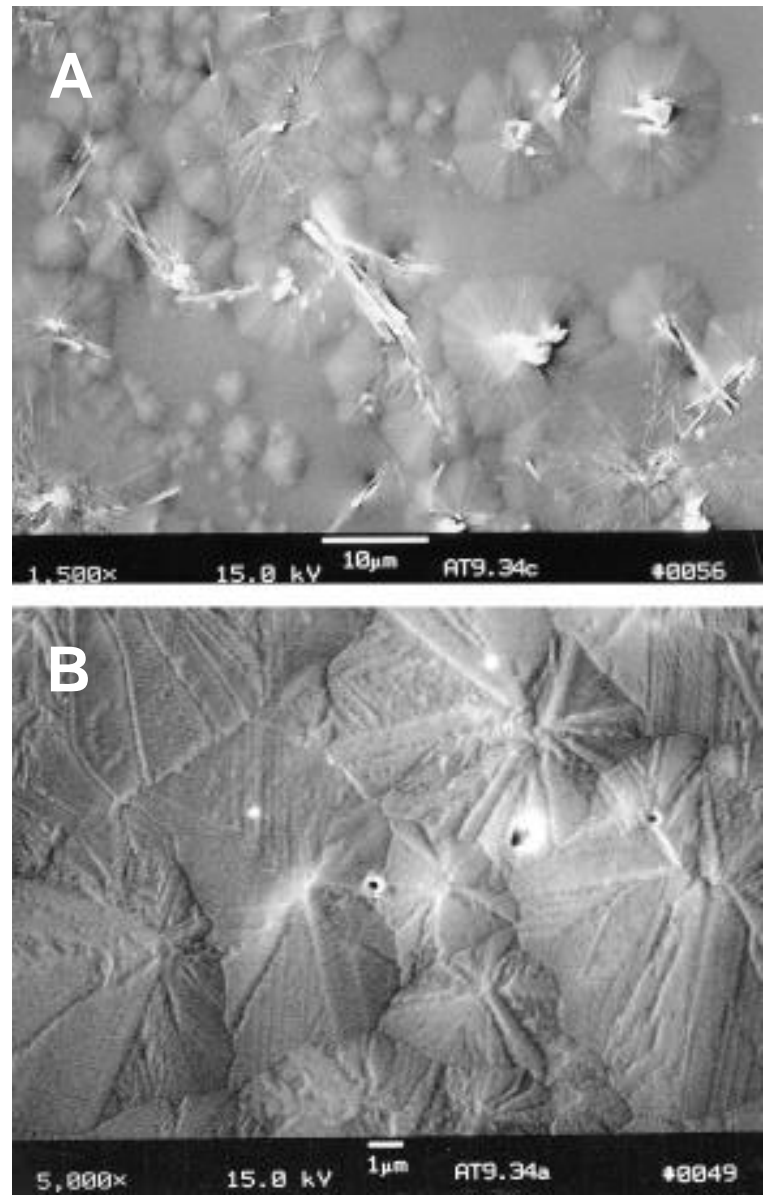

Figure 4: Secondary electron image of surface of the oxide scale formed on (A) Alloy 3, and (B) Alloy 2. Both samples were oxidized at $1100^{\circ} \mathrm{C}\left(60^{\circ} \mathrm{C}\right.$ water).

Figure 5 shows SEM backscattered images of scale cross-sections for Alloys 1,2, and 3. A continuous scale is observed to form on all alloys, with EDS revealing a silica composition. For Alloy 1, the scale is less than 10 $\mu \mathrm{m}$ thick in dry air, while water promotes the formation of scales thicker than $10 \mu \mathrm{m}$. For Alloy 2, scales in dry air are 10-15 $\mu \mathrm{m}$ thick, while water promotes the formation of scales thicker than $15 \mu \mathrm{m}$. For Alloys 1 and 2, these observations are consistent with the XRD analysis of the phase composition of the scales. For Alloy 3 , scales in dry air are $15-20 \mu \mathrm{m}$ thick, while water leads to the formation of a very thick layer $(\sim 100 \mu \mathrm{m})$ of external silica and a finely divided, multiphase interlayer near the alloy interface. Water promotes the growth of this multiphase interlayer in all alloys, but Alloy 3 is particularly sensitive to water accelerated growth of this interlayer. 


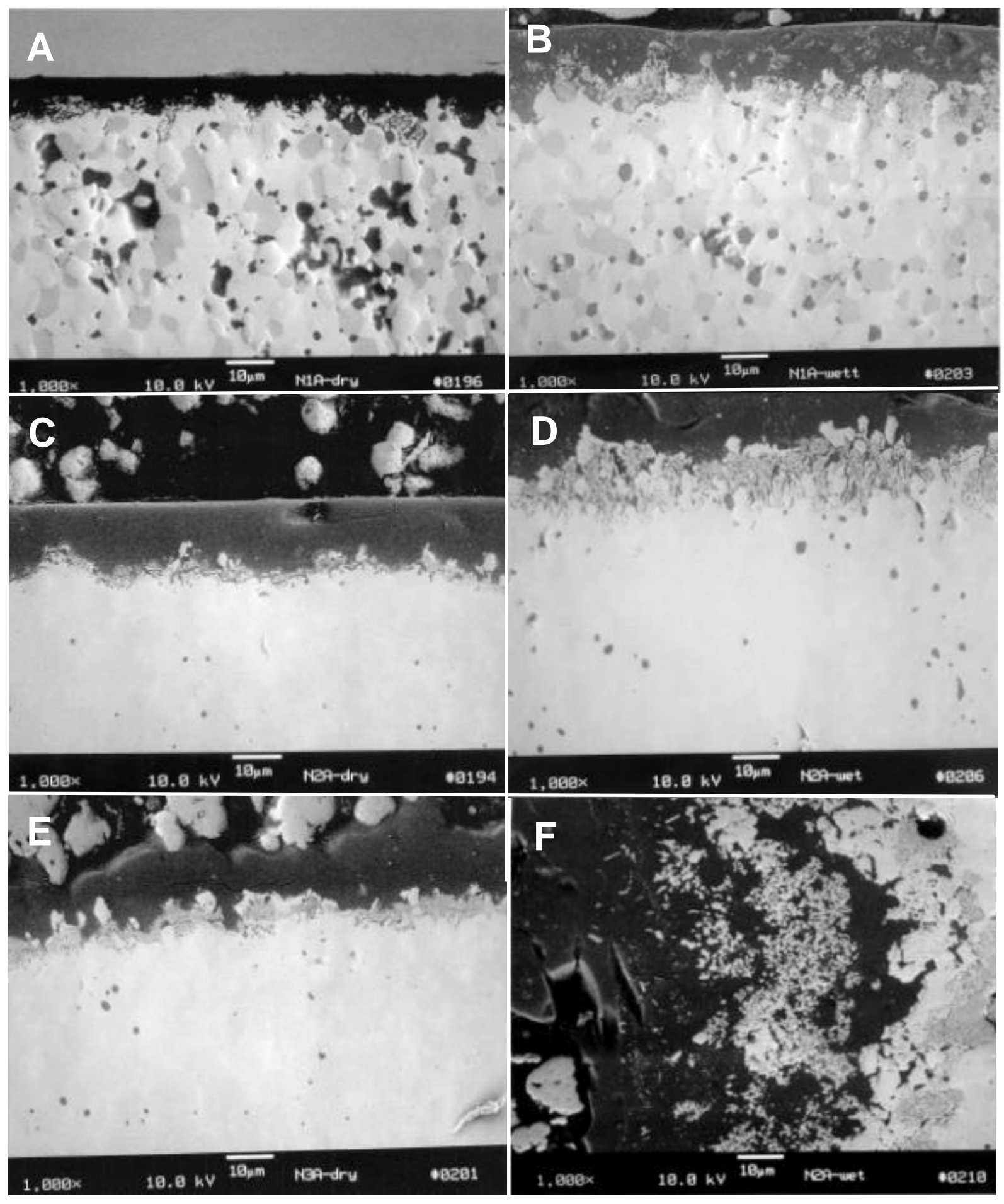

Figure 5: Backscattered electron image of scale cross-sections formed during oxidation at $1100^{\circ} \mathrm{C}$ for (A) Alloy 1 in dry air, (B) Alloy 1 in wet air, (C) Alloy 2 in dry air, (D) Alloy 2 in wet air, (E) Alloy 3 in dry air, (F) Alloy 3 in wet air. Wet air was set to $60^{\circ} \mathrm{C}$ water. The scale is horizontal and at the top of Figs. 5A-E. Scale is vertical and at left edge in Fig. 5F. 
Seen in greater detail in Figure 6, the interlayer appears as a fine, eutectic-like mixture of a bright Mo-rich phase (presumably Mo and/or $\mathrm{MoO}_{2}$ ) dispersed within a thin, continuous matrix of darker silica. Note that both micrographs are at the same magnification. However, EDS spatial resolution is insufficient to conclusively differentiate between areas that correspond to $\mathrm{Mo}$ or $\mathrm{MoO}_{2}$. All alloys form a continuous silica scale that contains varying amounts of subscale $\mathrm{Mo}$ and $\mathrm{MoO}_{2}$. However, $\mathrm{MoO}_{3}$ was not observed on or within the scale, and taken together, these observations imply that the external silica scale dramatically slows the inward transport of oxygen in all alloys.

The probable reactions for the oxidation of Alloys 1 and 2, which are dominated by the $\mathrm{T} 1$ phase, are:

$\mathrm{Mo}_{5} \mathrm{Si}_{3}+8 \mathrm{O}_{2} \rightarrow 5 \mathrm{MoO}_{2}+3 \mathrm{SiO}_{2}$

$\mathrm{Mo}_{5} \mathrm{Si}_{3}+3 \mathrm{O}_{2} \rightarrow 5 \mathrm{Mo}+3 \mathrm{SiO}_{2}$

For Alloy 3, the two silicon bearing phases, and in particular the $\mathrm{T} 2$ phase, must be involved in the oxidation reactions:

$$
\begin{aligned}
& 2 \mathrm{Mo}_{5} \mathrm{SiB}_{2}+5 \mathrm{O}_{2} \rightarrow \\
& 10 \mathrm{Mo}+2 \mathrm{SiO}_{2}+2 \mathrm{~B}_{2} \mathrm{O}_{3}
\end{aligned}
$$

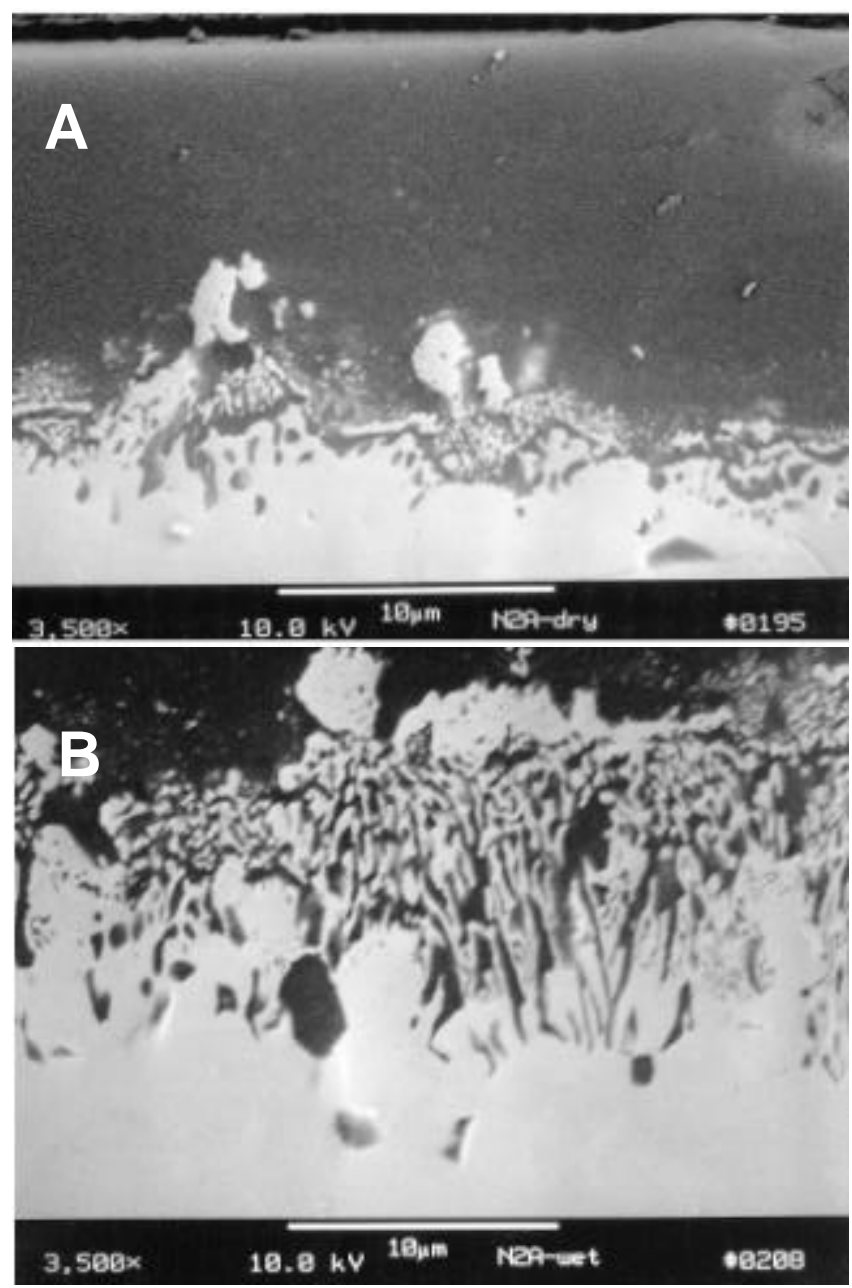

Figure 6: Backscattered electron image of scale crosssections formed during oxidation at $1100^{\circ} \mathrm{C}$ for Alloy 2 in (A) dry air, and (B) wet air set to $60^{\circ} \mathrm{C}$ water.

$2 \mathrm{Mo}_{5} \mathrm{SiB}_{2}+15 \mathrm{O}_{2} \rightarrow$

$$
10 \mathrm{MoO}_{2}+2 \mathrm{SiO}_{2}+2 \mathrm{~B}_{2} \mathrm{O}_{3}
$$

$\mathrm{Mo}_{3} \mathrm{Si}+\mathrm{O}_{2} \rightarrow 3 \mathrm{Mo}+\mathrm{SiO}_{2}$

$\mathrm{Mo}_{3} \mathrm{Si}+4 \mathrm{O}_{2} \rightarrow 3 \mathrm{MoO}_{2}+\mathrm{SiO}_{2}$

Isothermal mass loss measurements are planned to provide quantitative estimates of the oxidation rate kinetics for comparison to these batch oxidation test results. Higher temperature tests are also planned to determine if water vapor has a similar effect on the oxidation process at $1600^{\circ} \mathrm{C}$. High resolution Auger electron microscopy and possibly transmission electron microscopy will be used to examine the interlayer and to identify the phases and quantify their chemistry. 


\section{ACKNOWLEDGEMENT}

This report was prepared with the support of the U.S. Department of Energy (DOE) National Energy Technology Laboratory under Field Work Proposal number AL-00-360-011. Ames Laboratory is operated for the U.S. Dept. of Energy (DOE) by Iowa State University under contract No. W-7405-ENG-82.

\section{REFERENCES}

1. M.K. Meyer and M. Akinc, "Oxidation Behavior of Boron-Modified $\mathrm{Mo}_{5} \mathrm{Si}_{3}$ at $800-1300^{\circ} \mathrm{C}, " \mathrm{~J} . \mathrm{Am}$. Ceram. Soc., 79 [4], 938-44 (1996).

2. J.H. Schneibel, M.J. Kramer, O.Unal, and R.N. Wright, "Processing and Mechanical Properties of a Molybdenum Silicide with the Composition Mo-12Si-8.5B (at. \%)," Intermetallics, 9 [1], 25-31 (2001).

3. A.J. Thom, E. Summers, and M. Akinc, "Oxidation Behavior of Extruded $\mathrm{Mo}_{5} \mathrm{Si}_{3} \mathrm{~B}_{\mathrm{x}}-\mathrm{MoSi} \mathrm{H}_{2}-\mathrm{MoB}$ Intermetallics from $600^{\circ}-1600^{\circ} \mathrm{C}$," Intermetallics, in press. 